\section{Effects of malolactic fermentation on colour stability and phenolic composition of Petit Verdot red wines}

\author{
Pedro Miguel Izquierdo-Cañas, 1,2 Esteban \\ García-Romero, ${ }^{1}$ Adela Mena-Morales, ${ }^{3}$ \\ Sergio Gómez-Alonso ${ }^{2,3}$ \\ 'Instituto de la Vid y el Vino de Castilla- \\ La Mancha-IRIAF, Tomelloso; ${ }^{2}$ Parque \\ Científico-Tecnológico de Castilla-La \\ Mancha, Albacete; ${ }^{3}$ Instituto Regional de \\ Investigación Científica Aplicada, \\ Universidad de Castilla-La Mancha, \\ Ciudad Real, Spain
}

\begin{abstract}
In the present work we evaluate the effects of malolactic fermentation (MLF) on the colour parameters and polyphenolic composition of Petit Verdot red wines. MLF caused a significant decrease in colour intensity in wines, approximately $9 \%$. In line with that, the results showed a decrease in the concentration of anthocyanins (acylated and non-acylated), but an increase of the pyranothocyannins concentration. MLF did not produce important variations on the content of hydroxycinnamic acids derivatives, stilbenes and flavonols. Regarding flavan-3-ols, MLF caused a decrease in monomers, total flavan-3-ols and percentage of galloylation, and an increase on the percentage of prodelphinidins. However, no effect over mean degree of polymerisation was observed. Thus, it is unlikely that these changes may affect the acceptability of wines by consumers.
\end{abstract}

\section{Introduction}

Red winemaking includes several phases besides alcoholic fermentation (AF), being malolactic fermentation (MLF) and ageing of wine in barrels and/or in bottles between the main ones. The central purpose of MLF is to reduce wine acidity, transforming malic acid, a dicarboxylic acid, into lactic acid, a monocarboxylic acid. ${ }^{1}$ Moreover, during this process volatile compounds that enrich the wine's aromatic quality, together with those formed during $\mathrm{AF}$, are also formed. ${ }^{2,3}$

The influence of monomeric and polymeric phenolic compounds in the colour parameters and sensory quality of wine is obvious. Grape and wine phenolics belong to two main groups: flavonoid and nonflavonoid compounds. Flavonoids, located in grape skins, seeds and stems, include anthocyanins, flavan-3-0l monomers, oligomeric and polymeric proanthocyanidins, flavonols, flavanonols and flavones. Nonflavonoids, which derive primarily from the pulp and skins of grape berries, include hydroxycinnamic and hydroxybenzoic acid derivatives and stilbenes. All of them are important constituents of both grapes and wine due to their direct and indirect contribution to wine sensorial properties such as colour, flavour, astringency, bitterness and structure of the wines. ${ }^{4}$

On this context, the studies regarding the effects of MLF on wine aroma, biogenic amines content and other microbiological parameters are common. ${ }^{3,5-7}$ However, literature and studies about the consequences of MLF on red wine colour parameters and phenolic composition are scarce, although the empirical accumulated knowledge. , $^{1,89}$ Moreover, the effects of MLF on wine composition is usually measured by analysing the samples of wine taken immediately after the $\mathrm{AF}$ and then just finished the MLF and by hence there are no available information on the effect of the FML on the stability of phenolic compounds and wine color during wine aging.

Given the importance of phenolic compounds to the final quality, and therefore, to the consumer acceptance of red wines, in the present work we evaluate the differences in the colour parameters and phenolic composition of two sets of Petit Verdot red wines which have been identically elaborated and stored for a period of nine months before analysed, being the only difference between them that one of the sets has undergone the MLF.

\section{Materials and Methods}

\section{Fermentation assays}

Vinifications were carried out in the wine cellar of the Vine and Wine Institute of Castilla-La Mancha (Tomelloso, Castilla-La Mancha, Spain) using red grapes Vitis vinifera $c v$. Petit Verdot. They were harvested on the vintage 2013 at commercial maturity: $23.9^{\circ}$ Brix. For the winemaking, grapes were destemmed and distributed into three $100 \mathrm{~L}$ tanks, sulphited with $5 \mathrm{~g} / \mathrm{HL} \mathrm{SO}_{2}$ and inoculated with $25 \mathrm{~g} / \mathrm{HL}$ Uvaferm $\mathrm{VN}^{\circledR}$ yeast strain (Lallemand Inc., Montreal, Canada). AF was carried out at $25 \pm 2^{\circ} \mathrm{C}$. The fermentation was monitored daily by measuring the density and grape must was pressed upon reaching a density of $995 \mathrm{~g} / \mathrm{L}$. The completion of AF was carrying out at room temperature. After $\mathrm{AF}$, the wine in each tank was divided into two batches in 50 $\mathrm{L}$ tanks maintained at $22^{\circ} \mathrm{C}$. The first batch was sulphited until a final free $\mathrm{SO}_{2}$ concentration of $30.0 \mathrm{mg} / \mathrm{L}$ to avoid the development of MLF
Correspondence: Pedro Miguel Izquierdo-Cañas, Instituto de la Vid y el Vino de Castilla-La Mancha-IRIAF, Crta. Toledo-Albacete s/n., 13700 Tomelloso, Spain.

Tel: +34.926 .508060 - Fax: +34.926 .512610$

E-mail: pmizquierdo@jccm.es

Key words: Polyphenols; Colour; Malolactic fermentation; Petit Verdot.

Acknowledgements: PMIC and SGA thank the Fondo Social Europeo and the Junta de Comunidades de Castilla-La Mancha for co-funding their contracts through the INCRECYT program.

Received for publication: 3 February 2016

Revision received: 25 April 2016.

Accepted for publication: 26 April 2016

This work is licensed under a Creative Commons Attribution 3.0 License (by-nc 3.0).

(C) Copyright P.M. Izquierdo-Cañas et al., 2016

Licensee PAGEPress, Italy

Wine Studies 2016; 5:5795

doi:10.4081/ws.2016.5795

(batch without MLF). The second one was inoculated with a commercial lactic acid bacteria Alpha strain $\left(\mathrm{MBR}^{\circledR}\right)$, according to the manufacturer's instructions (Lallemand Inc.). MLF development was controlled by monitoring the L-malic acid concentration of the wines. When malic acid content reached values $\leq 0.2 \mathrm{~g} / \mathrm{L}$, the wines were sulphited until a final free $\mathrm{SO}_{2}$ concentration of $30.0 \mathrm{mg} / \mathrm{L}$. Finally all the wines (with and without MLF) were then cold-stabilised, filtered through 0.2 $\mathrm{m}$ filters and bottled and stored for nine months at controlled temperature at $16^{\circ} \mathrm{C}$ until analysis. Vinifications were carried out in triplicate and average values of the three tanks are presented.

\section{Wine analysis}

\section{Physicochemical analysis}

The wines were analytically characterised. The following parameters were determined: alcohol content, total acidity (expressed as tartaric acid), $\mathrm{pH}$, volatile acidity (expressed as acetic acid), L-malic acid, L-lactic acid, citric acid, colour intensity, tonality and shade following the official analytical methods established by the International Organisation of Vine and Wine. ${ }^{10}$

Colour parameters were obtained following the OIV method for the determination of chromatic characteristics according to CIELab (Resolution Oeno 1/2006) Method OIV-MA AS211 using an Agilent 8453 diode array spectrophotometer (Agilent Technologies, Santa Clara CA, USA) with a homemade program for spectra 
treatment. The measuring conditions were transmittance between 770 and $380 \mathrm{~nm}$ at 5 -nm intervals, 1-mm cuvettes, D65 illuminant, and a $10^{\circ}$ reference pattern observer. Results expressed were referred to $1-\mathrm{cm}$ optical length. ${ }^{10}$

Sample preparation for flavonols and hydroxycinnamic acid derivatives analysis

PCX solid phase extraction (SPE) cartridges (500 mg, $6 \mathrm{~mL}$; Bond Elut Plexa, Agilent, Palo Alto, CA, USA) allowed the isolation of nonanthocyanin phenolic compounds from wines, and these anthocyanin-free fractions were used to analyse flavonols and hydroxycinnamic acid derivatives. To carry out this separation, 3 $\mathrm{mL}$ of wine were diluted with $3 \mathrm{~mL}$ of $\mathrm{HCl} 0.1$ $\mathrm{N}$, and the prepared samples were then passed through the SPE cartridges that had been previously conditioned with $5 \mathrm{~mL}$ of methanol and $5 \mathrm{~mL}$ of water. After, the cartridges were washed with $5 \mathrm{~mL}$ of $\mathrm{HCl} 0.1 \mathrm{~N}$ and $5 \mathrm{~mL}$ of water, the anthocyanin-free fraction was eluted with $3 \times 5 \mathrm{~mL}$ of methanol. This eluate was dried in a rotary evaporator $\left(35^{\circ} \mathrm{C}\right)$ and re-dissolved in $1.5 \mathrm{~mL}$ of $20 \%$ methanol in water and directly injected into the high-performance liquid chromatography (HPLC) equipment.

\section{Analysis of monomeric phenolic com- pounds in wines by high-performance liq- uid chromatography}

Individual phenolic compounds were determined by HPLC-coupled with diode array detection-electrospray ionisation mass spectrometry (-DAD-ESI-MS/MS) following the conditions of previously described methods ${ }^{11,12}$ to the use of narrow bore, smaller particle size, chromatography columns. Analysis was performed on an Agilent 1100 series system equipped with a photodiode array detector (PDA) and a LC/MSD Trap VL ESI-MS/MS, both coupled to an Agilent ChemStation for data processing. For anthocyanin analysis, wines were filtered $(0.2 \mu \mathrm{m}$ Chromafil Pet; Macherey-Nagel, Düren, Germany) and injection volume was $10 \mu \mathrm{L}$. Separation was achieved on a narrow-bore column Zorbax Eclipse XDB-C18 (2.1 x $150 \mathrm{~mm}$; 3.5 um particle; Agilent), with pre-column Zorbax Eclipse XDB-C8 (2.1 x $12.5 \mathrm{~mm} ; 5 \mu \mathrm{m}$ particle; Agilent), both thermostated at $40^{\circ} \mathrm{C}$. Eluents used were (A) acetonitrile/water/ formic acid $(3: 88.5: 8.5 \mathrm{v} / \mathrm{v} / \mathrm{v})$, and (B) acetonitrile/ water/formic acid (50:41.5:8.5 v/v/v). The linear solvents' gradient for anthocyanin analysis was as follows: zero min, $6 \% \mathrm{~B} ; 10 \mathrm{~min}, 30 \% \mathrm{~B}$; 30 min, $50 \%$ B; 34 min, 100\% B; 36 min, 100\% B; 42 min, 4\% B; 50 min, 4\% B. For non-anthocyanin analysis, free-anthocyanin fractions (see sample preparation for flavonols and hydroxycinnamic acid derivatives analysis) were filtered $(0.2 \mu \mathrm{m}$ Chromafil Pet; Macherey-Nagel) and injection volume was 20 $\mu \mathrm{L}$. The same column was used while eluents were (A) acetonitrile/water/formic acid (3:88.5:8.5 v/v/v), (B) acetonitrile/water/formic acid (50:41.5:8.5 v/v/v), and (C) methanol/ water/formic acid (90:1.5:8.5 v/v/v). The linear solvents' gradient for non-anthocyanin analysis was as follows: zero min, $2 \% \mathrm{~B}$ and $0 \% \mathrm{C} ; 8$ min, 4\% $\mathrm{B}$ and $0 \% \mathrm{C} ; 37 \mathrm{~min}, 17 \% \mathrm{~B}$ and $13 \% \mathrm{C}$; $51 \mathrm{~min}, 30 \% \mathrm{~B}$ and $20 \% \mathrm{C} ; 51.5 \mathrm{~min}, 40 \% \mathrm{~B}$ and $30 \% \mathrm{C}$; $56 \mathrm{~min}, 50 \% \mathrm{~B}$ and $50 \% \mathrm{C}$; $57 \mathrm{~min}, 50 \%$ $\mathrm{B}$ and $50 \% \mathrm{C} ; 64 \mathrm{~min}, 4 \% \mathrm{~B}$ and $0 \% \mathrm{C}$. The use of a narrow-bore column allowed establishing a slow low rate $(0.19 \mathrm{~mL} / \mathrm{min})$. For identification, Ion Trap ESI-MS/MS detector was used in both positive (anthocyanins) and negative (flavonols, hydroxycinnamic acids) ion modes, setting the following parameters: dry gas $\mathrm{N}_{2}, 8$ $\mathrm{L} / \mathrm{min}$; drying temperature, $325^{\circ} \mathrm{C}$; nebulizer, $\mathrm{N}_{2}, 50$ psi; ionisation and fragmentation parameters were optimised by direct infusion of appropriate standard solutions (malvidin-30 -glucoside in positive ionisation mode; quercetin-3-0-glucoside and caftaric acid in negative ionisation mode); scan range, 50$1200 \mathrm{~m} / \mathrm{z}$. Identification was based on spectroscopic data (UV-Vis and MS/MS) obtained from authentic standards, when available, or previously reported data. ${ }^{12,13}$ Quantification was made using the DAD chromatograms recorded at $520 \mathrm{~nm}$ (anthocyanins), $360 \mathrm{~nm}$ (flavonols), $320 \mathrm{~nm}$ (hydroxycinnamic acid derivatives), and the calibration graphs of the respective standards (R2>0.999). Quantification of noncommercial compounds was made according to the calibration graphs of the most similar compounds. Hence, anthocyanins were expressed as $\mathrm{mg} / \mathrm{L}$ of malvidin-3-0-glucoside, flavonols were expressed as mg/L of quercetin-3-0-glucoside, and hydroxycinnamic acid derivatives were expressed as $\mathrm{mg} / \mathrm{L}$ of trans-caftaric acid.

\section{Sample preparation for flavan-3-ols analysis}

Flavan-3-ols (monomers, B-type dimers, and polymeric proanthocyanidins) were isolated from wines using SPE on C18 cartridges (Seppak Plus C18; Waters Corp., Millipore, MA, USA; cartridges filled with $820 \mathrm{mg}$ of adsorbent). A mixture of $2 \mathrm{~mL}$ of each wine with 6 $\mathrm{mL}$ of water was then passed through the $\mathrm{C} 18$ cartridge, which had been previously conditioned with methanol $(5 \mathrm{~mL})$ and water (5 $\mathrm{mL}$ ); after the cartridge was dried under reduced pressure, methanol $(15 \mathrm{~mL})$ and ethyl acetate $(5 \mathrm{~mL})$ were added in order to recover adsorbed phenolics; after the solvent was evaporated in a rotary evaporator $\left(35^{\circ} \mathrm{C}\right)$, the residue was dissolved in methanol $(2 \mathrm{~mL})$ and stored at $-18^{\circ} \mathrm{C}$ until analysis.

Identification and quantification flavan-3ols and stilbenes using multiple reaction monitoring high-performance liquid chromatography-electrospray ionisation mass spectrometry

The analysis was carried out using a HPLC
Agilent 1200 series system equipped with DAD (Agilent Technologies) and coupled to an $\mathrm{AB}$ Sciex 3200 TRAP (Applied Biosystems, Carlsbad, CA, USA) with triple quadrupole, turbo ESI-MS/MS system. The chromatographic system was managed and the mass spectra data was processed using the Analyst MSD software (Applied Biosystems).

Structural information concerning the proanthocyanidins was obtained using the pyrogallol-induced acid-catalyzed depolymerisation method. ${ }^{14}$ The reaction consisted of adding $0.50 \mathrm{~mL}$ of the pyrogallol solution (100 $\mathrm{g} / \mathrm{L}$ pyrogallol plus $20 \mathrm{~g} / \mathrm{L}$ of ascorbic acid in 0.3 $\mathrm{N} \mathrm{HCl}$ ) to $0.25 \mathrm{~mL}$ of the sample in methanol and incubating $40 \mathrm{~min}$ at $30^{\circ} \mathrm{C}$. The hydrolysis reaction was stopped by adding $2.25 \mathrm{~mL}$ of sodium acetate $(67 \mathrm{mM})$. An aliquot of $2 \mathrm{~mL}$ of the reacted sample was placed in a vial and injected directly into the equipment for analysis. The samples, before and after the acid-catalyzed depolymerisation reaction, were injected $(20 \mathrm{~L})$ into an Ascentis $\mathrm{C} 18$ reversed-phase column ( $150 \mathrm{~mm} \times 4.6 \mathrm{~mm}$ with $2.7 \mathrm{~m}$ of particle size) (Supelco, Bellefonte, PA, USA) with the temperature controlled at $16^{\circ} \mathrm{C}$. The solvents and gradients used for this analysis and the multiple reaction monitoring settings as well as all the mass transitions $(\mathrm{m} / \mathrm{z})$ for identification and quantitation were according to the methodology reported by Lago-Vanzela. ${ }^{13}$

\section{Statistical analysis}

The paired Student $t$-test was used to identify any significant differences between chemical analysis results and volatile compounds. IBM SPSS Statistics 22.0 software was used for both analyses.

\section{Results and Discussion}

\section{Oenological parameters and colour}

The oenological and colour parameters are shown in Table 1 . The values of total acidity were in agreement with the normal content found in Spanish wines. ${ }^{15}$ As expected, MLF produced an increase of wine $\mathrm{pH}$, a decrease of total acidity and a slight increase in volatile acidity. Wines without MLF, showed high values of colour intensity, indicating a good potential for ageing. MLF caused significant decreases in colour intensity in the wines, about $9 \%$. These results are similar to those observed by Martínez-Pinilla ${ }^{8}$ in Tempranillo and other varieties wines when studying the effects of MLF. ${ }^{16}$

Statistical significative differences were observed in the CIELAB parameters a* (redness), $b^{*}$ (yellow) and $\mathrm{L}^{*}$ (lightness) among wines without and with MLF. Although these differences were quite small, wines which 
undergone MLF showed higher lightness and also higher contributions of components $a^{*}$ and $\mathrm{b}^{*}$ to their colour.

All these changes have been attributed to three different phenomena: firstly, the increase of $\mathrm{pH}$ that occurs in wine during MLF produces a reduction of the proportion of anthocyanins in form of flavilium cation (the red colored form of the anthocyanins) and therefore reduces the color intensity and increases $\mathrm{L}^{*}$. Secondly, the dissociation of the copigmentation complexes, probably due to the ionic shifts occurring during the MLF. ${ }^{17}$ And finally, the formation of new and stable pigments resistant not only to the bisulfite addition but also to $\mathrm{pH}$ changes and oxidation ${ }^{18,8}$ but showing lower molar extinction coefficient (increase of wine lightness) and orangish colour (higher contribution to b* component).

\section{Anthocyanins}

Table 2 shows the concentrations (mg/L) of the different anthocyanins identified in the wines without and with MLF. The anthocyanin profile and concentration of wines is largely dependent on grape variety and climatic and agronomic conditions, but also on the technology applied during winemaking, and the reactions that take place during maturation and ageing in wood. ${ }^{1}$ The main anthocyanins identified in Vitis vinifera spp. grapes and wines are the 3-0-glucosides, 3-0-acetyl glucosides and 3-0-p-coumaroyl glucosides of delphinidin, cyanidin, petunidin, peonidin and malvidin, as well as the 3-0-caffeoyl glucosides of malvidin and peonidin. ${ }^{19,20}$

The results show a lower concentration of anthocyanins (acylated and non-acylated) and a higher content of pyranoanthocyanins in wines with MLF, which seems to indicate that anthocyanins are less stable in the wine subjected to MLF. The differences in the content of anthocyanins does not depend on the type of aglycone since for both disubstituted and trisubstituted anthocyanins it was around $10 \%$, but the difference in acylated anthocyanins is slightly superior to that in the non acylated anthocyanins (14 vs 9\% respectively). These results are similar with those observed by Martínez-Pinilla. ${ }^{8}$ These authors observed a decrease of $30 \%$ in the total anthocyanins concentration and attributed this diminution to the participation of monomeric anthocyanins in the formation of polymeric structures which tend to precipitate, and also to degradation and oxidation of the anthocyanins. Similar results were also observed by Burns. ${ }^{21}$

With regard to the pyranoanthocyanins, the contents of vitisin and acetyl vitisin A were higher in wines with MLF. Burns and colleagues ${ }^{21}$ found lower concentrations of vitisin $\mathrm{B}$ in wines with FML.

\section{Hydroxycinnamic acid derivatives}

\section{and stilbenes}

The only hydroxycinnamic acids (Table 3) to tartaric acid esters forms, while the free forms (caffeic, coumaric and ferulic acids) were below the quantification limits. In all the

Table 1. Oenological and colour parameters of Petit Verdot wines without and with malolactic fermentation.

\begin{tabular}{lcc} 
& Without MLF & With MLF \\
Alcohol content $(\% \mathrm{v} / \mathrm{v})$ & $14.65 \pm 0.01$ & $14.61 \pm 0.08$ \\
Total acidity $(\mathrm{g} / \mathrm{L})$ & $4.94 \pm 0.09$ & $4.16 \pm 0.07^{\circ}$ \\
\hline $\mathrm{pH}$ & $3.84 \pm 0.01$ & $3.92 \pm 0.04^{\circ}$ \\
Volatile acidity $(\mathrm{g} / \mathrm{L})$ & $0.28 \pm 0.01$ & $0.31 \pm 0.03^{\circ}$ \\
\hline L-malic acid $(\mathrm{g} / \mathrm{L})$ & $1.37 \pm 0.01$ & $0.00 \pm 0.00^{\circ}$ \\
L-lactic acid $(\mathrm{g} / \mathrm{L})$ & $0.05 \pm 0.06$ & $0.98 \pm 0.04^{\circ}$ \\
\hline Citric acid $(\mathrm{g} / \mathrm{L})$ & $0.29 \pm 0.00$ & $0.26 \pm 0.02^{\circ}$ \\
$\mathrm{L}^{*}$ & $12.15 \pm 0.16$ & $12.99 \pm 0.44^{\circ}$ \\
\hline $\mathrm{a}^{*}$ & $43.37 \pm 0.18$ & $44.47 \pm 0.72^{\circ}$ \\
$\mathrm{b}^{*}$ & $20.58 \pm 0.27$ & $21.67 \pm 0.70^{\circ}$ \\
\hline Colour intensity & $10.51 \pm 0.02$ & $9.55 \pm 0.11^{\circ}$ \\
Tonality & $0.58 \pm 0.00$ & $0.60 \pm 0.00^{\circ}$ \\
\hline
\end{tabular}

MLF, malolactic fermentation; $\mathrm{L}^{*}$, lightness; $\mathrm{a}^{*}$, redness; $\mathrm{b}^{*}$, yellow. Values are the mean of triplicate assays. ${ }^{\circ}$ Statistically significant differences $(\mathrm{P} \leq 0.05)$.

Table 2. Concentration of anthocyanins $(\mathrm{mg} / \mathrm{L})$ in Petit Verdot wines without and with malolactic fermentation.

\begin{tabular}{|c|c|c|}
\hline 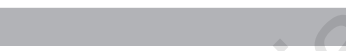 & Whitout MLF & With FML \\
\hline Delphinidin-3-glc & $4.54 \pm 0.25$ & $4.07 \pm 0.07 *$ \\
\hline Cyanidin-3-glc & $0.23 \pm 0.01$ & $0.21 \pm 0.01 *$ \\
\hline Petunidin-3-glc & $9.81 \pm 0.19$ & $8.80 \pm 0.05^{*}$ \\
\hline Peonidin-3-glc & $2.55 \pm 0.08$ & $2.39 \pm 0.01^{*}$ \\
\hline Malvidin-3-glc & $144.33 \pm 2.77$ & $132.19 \pm 4.80^{*}$ \\
\hline Delphinidin-3-acglc & $3.22 \pm 0.05$ & $2.71 \pm 0.11^{*}$ \\
\hline Petunidin-3- acglc & $6.35 \pm 0.11$ & $5.60 \pm 0.06^{*}$ \\
\hline Peonidin-3-acglc & $2.14 \pm 0.02$ & $1.91 \pm 0.05^{*}$ \\
\hline Malvidin-3-acglc & $81.11 \pm 2.25$ & $70.80 \pm 3.01^{*}$ \\
\hline trans-delphinidin-3-cmglc & $0.88 \pm 0.04$ & $0.74 \pm 0.04 *$ \\
\hline trans-petunidin-3-cmglc & $0.90 \pm 0.02$ & $0.87 \pm 0.02 *$ \\
\hline trans-peonidin-3-cmglc & $0.47 \pm 0.01$ & $0.39 \pm 0.00^{*}$ \\
\hline cis-malvidin-3-cmglc & $0.81 \pm 0.12$ & $0.53 \pm 0.04 *$ \\
\hline trans-malvidin-3-cmglc & $17.91 \pm 0.37$ & $15.65 \pm 0.63 *$ \\
\hline Malvidin-3-cfgcl & $2.25 \pm 0.17$ & $2.20 \pm 0.15$ \\
\hline Vitisin A & $16.76 \pm 0.77$ & $21.78 \pm 0.60 *$ \\
\hline Vitisin B & $9.68 \pm 0.66$ & $9.59 \pm 0.14$ \\
\hline Acetyl vitisin A & $12.57 \pm 0.45$ & $15.38 \pm 0.43^{*}$ \\
\hline Acetyl vitisin B & $3.51 \pm 0.30$ & $3.81 \pm 0.01$ \\
\hline Coumaroyl vitisin A & $5.04 \pm 0.23$ & $6.19 \pm 0.09 *$ \\
\hline$\sum$ Trisubstituted anthocyanins & $5.39 \pm 0.05$ & $4.90 \pm 0.03^{*}$ \\
\hline$\sum$ Disubstituted anthocyanins & $272.09 \pm 5.06$ & $244.17 \pm 8.42 *$ \\
\hline$\sum$ Piranoanthocyanins & $47.56 \pm 0.95$ & $56.75 \pm 1.80^{*}$ \\
\hline$\sum$ Non-acylated anthocyanins & $161.46 \pm 2.25$ & $147.66 \pm 4.78^{*}$ \\
\hline$\sum$ Acylated anthocyanins & $116.03 \pm 2.72$ & $101.40 \pm 3.70^{*}$ \\
\hline$\sum$ Total anthocyanins & $325.04 \pm 7.38$ & $305.80 \pm 9.74 *$ \\
\hline
\end{tabular}

MLF, malolactic fermentation. Values are the mean of triplicates. ${ }^{*}$ Statistically significant differences $(\mathrm{P} \leq 0.05)$. 
analysed wines, the trans-form of the acids presented higher concentrations than its $\mathrm{cis}$ isomer and, as reported in other red wine varieties ${ }^{22}$ the trans-caftaric acid was by far the major compound.

MLF did not produce important effects on the total content of hydroxycinnamic acid derivatives, however slight differences in the concentration of all of them were observed, although for trans-caftaric and trans-coutaric acids the changes were not statistically significant. The cis-coutaric acid was that experimenting a higher proportional difference, but his absolute concentración was always lower than $1 \mathrm{mg} / \mathrm{L}$. These results are similar to that found by ${ }^{23,24}$ showed losses of hydroxycinnamic acid derivates that tartaric esters were hydrolysed to their corresponding free forms during MLF. Chescheir and colleagues ${ }^{25}$ who demonstrated cinnamic esterase activity in 0 . oeni. The different esterasic activity of the lactic acid bacteria strains responsible for the MLF could expalin the results found in these studies. $^{26,27}$ Regarding to stilbenes, Petit Verdot wines elaborated for this study did not contained resveratrol in detectable levels, and only cis and trans isomers of piceid were quantified. The results presented in Table 3 indicate that the MLF had no appreciable effect on the concentration of these compounds. Similar results have been obtained by other authors. ${ }^{8,23}$

\section{Flavonols}

Table 4 shows the flavonols content in wines without and with MLF, displaying all wines values in the range of other red wines. ${ }^{28}$

Regarding the flavonol profile, myricetin-3 glucoside was the main flavonol found in Petit Verdot both without and with MLF, being in good agreement with other studies..$^{29,30}$ Syringetin-3-glucoside was the second mayor flavonol in these vines, followed of quercetin3 -glucuronide and laricitrin-3-glucoside.

Flavonols are present in the grape exclusively in the form of glycosides and the presence of flavonols aglicones in wine is attributed to hydrolysis processes, being unclear if they are chemical or enzymatic and lactic acid bacteria glycosidase enzymes could have some impact on wine flavonols. ${ }^{30}$ In this study, the MLF did not cause important changes neither the profile nor concentration of flavonols, although some slight statistically significant differences, with lower concentration of the derivatives of kaempferol, myricetin and laricitrin were observed in wines subjected to MLF. These results are similar with those obtained when MLF was carried out in oak barrels ${ }^{8}$ and those obtained when stainless steel tanks were employed. ${ }^{23}$

\section{Flavan-3-ols}

As in the case of flavonols, hydroxycinnamic acid and stilbenes, there are very few studies that have focused on study of wine flavan-3-ols comparing their stability in wines with have undergone the MLF and wines with only AF. The results obtained are shown in Table 5 . Wine subjected to MLF showed lower concentrations for almost all the analysed flavan-3ols, although for a high proportion of the com- pounds the changes were not statistically significant. Total flavan-3-ols content was $22.6 \%$ lower in the wines with MLF, being flavan-3-ols the group of phenolic compounds showing the highest differences between the two sets of wines. Previous works analysing flavan-3-ols of different varietal red wines before and after

Table 3. Concentration of hydroxycinnamic acid derivatives and stilbenes (mg/L) in Petit Verdot wines without and with malolactic fermentation.

\begin{tabular}{lcc} 
& Without MIFF & With MIF \\
trans-caftaric acid & $52.01 \pm 2.09$ & $48.64 \pm 2.33$ \\
trans-coutaric acid & $5.15 \pm 0.16$ & $4.83 \pm 0.26$ \\
\hline cis-coutaric acid & $0.98 \pm 0.01$ & $0.52 \pm 0.02^{*}$ \\
trans-fertaric acid & $5.34 \pm 0.09$ & $5.23 \pm 0.03^{*}$ \\
\hline$\sum$ Hydroxycinnamic acid derivatives & $63.48 \pm 2.16$ & $59.22 \pm 2.64^{*}$ \\
trans-piceid & $4.18 \pm 0.15$ & $3.65 \pm 1.05$ \\
\hline cis-piceid & $4.59 \pm 1.02$ & $4.04 \pm 0.13$ \\
$\sum$ Stilbenes & $8.77 \pm 1.17$ & $7.69 \pm 1.18$
\end{tabular}

MLF, malolactic fermentation. Values are the mean of triplicates. *Statistically significant differences $(\mathrm{P} \leq 0.05)$.

Table 4. Concentration of flavonols $(\mathrm{mg} / \mathrm{L})$ in Petit Verdot wines without and with malolactic fermentation.

\begin{tabular}{|c|c|c|}
\hline & Without MLF & With MLF \\
\hline Kaempferol-3-glucoside & $0.37 \pm 0.06$ & $0.33 \pm 0.06$ \\
\hline Kaempferol & $1.05 \pm 0.00$ & $0.95 \pm 0.03^{*}$ \\
\hline$\sum$ Monosustituted & $1.42 \pm 0.06$ & $1.28 \pm 0.03 *$ \\
\hline Querecetin-3-glucoside & $4.43 \pm 0.36$ & $4.39 \pm 0.44$ \\
\hline Querecetin-3-galactoside & $1.50 \pm 0.05$ & $1.53 \pm 0.01$ \\
\hline Querecetin-3-glucuronide & $8.65 \pm 0.09$ & $8.75 \pm 0.09$ \\
\hline Querecetin-3-rutinoside & $0.35 \pm 0.05$ & $0.33 \pm 0.03$ \\
\hline Querecetin & $4.80 \pm 0.29$ & $4.73 \pm 0.27$ \\
\hline Isorhamnetin-3-glucoside & $1.39 \pm 0.07$ & $1.39 \pm 0.06$ \\
\hline Isorhamnetin-3-galactoside & $0.17 \pm 0.01$ & $0.16 \pm 0.00$ \\
\hline Isorhamnetin & $0.34 \pm 0.01$ & $0.34 \pm 0.02$ \\
\hline$\sum$ Disustituted & $21.63 \pm 0.22$ & $21.62 \pm 0.28$ \\
\hline Myricetin-3-glucoside & $12.33 \pm 0.11$ & $11.65 \pm 0.03 *$ \\
\hline Myricetin-3-galactoside & $1.78 \pm 0.02$ & $1.67 \pm 0.00^{*}$ \\
\hline Myricetin-3-glucuronide & $2.19 \pm 0.03$ & $2.15 \pm 0.00 *$ \\
\hline Myricetin & $1.62 \pm 0.12$ & $1.44 \pm 0.12$ \\
\hline Laricitrin-3-glucoside & $6.78 \pm 0.24$ & $6.57 \pm 0.15$ \\
\hline Laricitrin & $0.17 \pm 0.00$ & $0.21 \pm 0.00^{*}$ \\
\hline Syringetin-3-glucoside & $9.87 \pm 0.49$ & $9.85 \pm 0.27$ \\
\hline Syringetin-3-galactoside & $0.32 \pm 0.01$ & $0.32 \pm 0.01$ \\
\hline Syringetin & $0.23 \pm 0.01$ & $0.23 \pm 0.01$ \\
\hline$\sum$ Trisustituted & $35.29 \pm 0.77$ & $34.07 \pm 0.36^{*}$ \\
\hline$\sum$ Total flavonols & $58.34 \pm 1.05$ & $56.96 \pm 0.67$ \\
\hline$\sum$ Kaempferol-type & $1.42 \pm 0.06$ & $1.28 \pm 0.03 *$ \\
\hline$\sum$ Quericitin-type & $19.73 \pm 0.16$ & $19.73 \pm 0.23$ \\
\hline$\sum$ Isorhamnetin-type & $1.90 \pm 0.06$ & $1.89 \pm 0.05$ \\
\hline$\sum$ Myricetin-type & $17.92 \pm 0.04$ & $16.90 \pm 0.08^{*}$ \\
\hline$\sum$ Laricitrin-type & $6.96 \pm 0.24$ & $6.77 \pm 0.15$ \\
\hline$\sum$ Syringetin-type & $10.41 \pm 0.49$ & $10.39 \pm 0.29$ \\
\hline
\end{tabular}

MLF, malolactic fermentation. Values are the mean of triplicates. *Statistically significant differences ( $\leq 0.05)$. 
Table 5. Concentration of flavan-3-ols $(\mathrm{mg} / \mathrm{L})$ in Petit Verdot wines without and with malolactic fermentation.

\begin{tabular}{lcc} 
& Without MIFF & With MIF \\
Catechin & $26.57 \pm 2.67$ & $22.98 \pm 0.91^{*}$ \\
Epicatechin & $12.28 \pm 2.83$ & $9.55 \pm 0.84$ \\
\hline Galocatechin & $5.39 \pm 0.16$ & $4.32 \pm 0.11^{*}$ \\
Epigalocatechin & $2.13 \pm 0.06$ & $2.10 \pm 0.01$ \\
\hline Epicatechin gallate & $0.26 \pm 0.03$ & $0.19 \pm 0.03^{*}$ \\
$\sum$ Monomers & $46.64 \pm 5.76$ & $39.15 \pm 1.90^{*}$ \\
\hline Procyanidin B1 & $11.36 \pm 0.79$ & $10.95 \pm 0.52$ \\
Procyanidin B2 & $4.36 \pm 0.63$ & $3.68 \pm 0.71$ \\
\hline Procyanidin B4 & $1.16 \pm 0.31$ & $1.03 \pm 0.17$ \\
Unknown procyanidin dimer & $0.88 \pm 0.04$ & $0.88 \pm 0.29$ \\
\hline$\sum$ Dimers & $17.78 \pm 1.77$ & $16.55 \pm 1.69$ \\
mDP & $2.42 \pm 0.18$ & $2.44 \pm 0.15$ \\
\hline Galloilation (\%) & $2.72 \pm 0.11$ & $2.16 \pm 0.45^{*}$ \\
Prodelphinidins (\%) & $26.36 \pm 1.14$ & $29.65 \pm 1.26^{*}$ \\
\hline$\sum$ Flavan-3-ols & $359.99 \pm 25.78$ & $278.63 \pm 46.84^{*}$ \\
\hline
\end{tabular}

MLF, malolactic fermentation; mDP, mean degree of polymerisation. Values are the mean of triplicates. ${ }^{*}$ Statistically significant differences $(\mathrm{P} \leq 0.05)$.

MLF also found important decreases in flavan3-ols content during MLF. ${ }^{8}$ These changes could be explained considering the participation of flavan-3-ols in condensation reactions and a later precipitation of the polymeric compounds formed. However, the mean degree of polymerisation (mDP) remains almost constant, and condensation reactions with anthocyanins seems hardly probable as cause of this decrease, since free anthocyanin content of wines which undergo MLF was higher than that of the wines not subjected to MLF, in which total flavan-3-ols content was higher. Regarding to the proanthocyanidins percentages of galloylation and prodelphinidins, our results seems to indicate that Petit Verdot wines subjected to MLF contains a higher proportion of flavan-3-ols coming from grape skins, as in this wine flavan-3-ols showed a slight, but statistically significant, higher percentage, of prodelphinidis and a lower percentage of galloylation.

\section{Conclusions}

The usual way of studying the effect of MLF on wine phenolic composition is analysing the wine just after the fermentation analysis, wait until the wine complete the later MLF and then analyse again the phenolic composition of the wine. In these studies the differences observed in the colour parameters and phenolic composition of the wines before and after MLF could be due to lactic acid bacteria enzymes and metabolites, and also to different chemical reactions, precipitation, etc. However, the effect of MLF is not limited to the time while
LABs are growing in wine, changes occurred in wine during MLF (pH and acidity changes, accumulation of dicacetyl, etc.) affect also the stability of phenolic compounds and wine colour during wine storage.

To overcome these limitations, when designing this study we decided to let both kinds of wine, those subjected only to AF and those which have undergone both AF and MLF, to stabilise for 9 months after bottling.

Wines not submitted to MLF maintained, after 9 months of storage, greater colour intensity, higher anthocyanin content and lower pyranoanthocyanins content than those, which underwent MLF. Among the other phenolic compounds, also related to wine colour and stability, flavan-3-ols were those most affected, with a concentration decrease higher than $20 \%$ in wines with underwent FML.

Although the changes observed in colour intensity and chromatic characteristics were statistically significant, they were not very important from a quantitatively point of view. Hence, it is unlikely that these changes may affect the acceptability of wines by consumers.

\section{References}

1. Moreno-Arribas MV, Gómez-Cordovés C, Martín-Álvarez PJ. Evolution of red wine anthocyanins during malolactic fermentation, postfermentative treatments and ageing with lees. Food Chem 2008;109: 149-58.

2. Pozo-Bayon MA, Alegría EG, Polo MC, et al. Wine volatile and amino acid composition after malolactic fermentation: effect of
Oenococcus oeni and Lactobacillus plantarum starter cultures. J Agr Food Chem 2005;53:8729-35.

3. Izquierdo-Cañas PM, García-Romero E, Gómez-Alonso S, Palop-Herreros MLL. Changes in the aromatic composition of Tempranillo wines during spontaneous malolactic fermentation. J Food Comp Anal 2008;21:724-30.

4. Garrido J, Borges F. Wine and grape polyphenols. A chemical perspective. Food Res Int 2011;44:3134-48.

5. Bartowsky E, Borneman AR. Genomic variations of Oenococcus oeni strains and the potential to impact on malolactic fermentation and aroma compounds in wines. Appl Microbiol Biot 2011;92:441-7.

6. Terrade N, Noël R, Couillaud R, Mira de Orduña R. A new chemically defined medium for wine lactic acid bacteria. Food Res Int 2009;42:363-7.

7. Izquierdo-Cañas PM, Ruíz-Pérez P, Seseña-Prieto S, Palop-Herreros ML. Ecological study of lactic acid microbiota isolated from Tempranillo wines of Castilla-La Mancha. J Biosci Bioeng 2009;108:220-4.

8. Martínez-Pinilla 0, Martínez-Lapuente L, Guadalupe Z, Ayestarán B. Sensory profiling and changes in colour and phenolic composition produced by malolactic fermentation in red minority varieties. Food Res Int 2012;46:286-93.

9. Bruns TR, Osborne JP. Loss of Pinot noir wine color and polymeric pigment after malolactic fermentation and potential causes. Am J Enol Viticult 2015;66:130-7.

10. OIV. Compendium of international methods of wine and must analysis. Mendoza, Argentina: Organización Internacional de la Viña y el Vino; 2014.

11. Romero E, Hermosín-Gutiérrez I. Flavonol profiles of Vitis vinifera red grapes and their single-cultivar wines. J Agr Food Chem 2007;55:992-1002.

12. Castillo-Muñoz N, Gómez-Alonso S, García-Romero E, et al. Flavonol 3-0-glycosides series of Vitis vinifera cv. Petit Verdot red wine grapes. J Agr Food Chem 2009;57: 209-19.

13. Lago-Vanzela ES, Da-Silva R, Gomes E, et al. Phenolic composition of the edible parts (flesh and skin) of Bordô grape (Vitis labrusca) using HPLC-DAD-ESIMS/MS. J Agr Food Chem 2011;59:1313646.

14. Bordiga M, Coïsson JD, Locatelli M, et al. Pyrogallol: an alternative trapping agent in proanthocyanidins analysis. Food Anal Method 2013;6:148-56.

15. Escudero-Gilete ML, González-Miret ML, Heredia FJ. Implications of blending wines on the relationships between the colour and the anthocyanic composition. Food 
Res Int 2010;43:745-52.

16. Ruiz P, Izquierdo-Cañas PM, Seseña S, et al. Malolactic fermentation and secondary metabolite production by Oenococcus oeni strains in low $\mathrm{pH}$ wines. J Food Sci 2012;77:579-85.

17. Boulton R. The copigmentation of Anthocyanins and its role in the color of red wine: a critical review. Am J Enol Viticult 2001;52:67-87.

18. Asenstorfer RE, Hayasaka Y, Jones GP. Isolation and structures of oligomeric wine pigments by bisulphite mediated ionexchange chromatography. J Agr Food Chem 2001;49:5957-63.

19. Atanasova V, Fulcrand H, Cheynier V, Moutounet M. Effect of oxygenation on polyphenol changes occurring in the course of winemaking. Anal Chim Acta 2002;458:15-27.

20. Monagas M, Gómez-Cordovés C, Bartolomé B. Evolution of polyphenols in red wines from Vitis vinifera L. during aging in bottle. I. Anthocyanins and pyranoanthocyanins. Eur Food Res Technol 2005;220:607-14.

21. Bruns TR, Osborne JP. Impact of malolactic fermentation on the color and color stability of Pinot noir and Merlot Wine. Am J Enol Viticult 2013;64:370-7.

22. Ginjom I, D’Arcy B, Caffin N, Gidley M. Phenolic compound profiles in selected Queensland red wines at all stages of the wine-making process. Food Chem 2011;125:823-34.

23. Hernández T, Estrella I, Carlavilla D, et al. Phenolic compounds in red wine subjected to industrial malolactic fermentation and aging on lees. Anal Chim Acta 2006;563: 116-25.

24. Cabrita MJ, Torres M, Palma V, et al. Impact of malolactic fermentation on low molecular weight phenolic compounds. Talanta 2008;74:1281-6.

25. Chescheir S, Philbin D, Osborne JP. Impact of Oenococcus oeni on wine hydroxycinnamic acids and volatile phenol production by Brettanomyces bruxellensis. Am J Enol Viticult 2015;66:357-63.

26. Pérez-Martín F, Seseña-Prieto S, Izquierdo-Cañas PM, Palop-Herreros MLL. Esterase activity of lactic acid bacteria isolated from malolactic fermentation of red wines. Int J Food Microbiol 2013;163:153-
8.

27. Pérez-Martín F, Izquierdo-Cañas PM, Seseña-Prieto $\mathrm{S}$, et al. Aromatic compounds released from natural precursors by selected Oenococcus oeni strains during malolactic fermentation. Eur Food Res Technol 2015;240:609-18.

28. Hermosín-Gutiérrez I, Castillo-Muñoz N, Gómez-Alonso S, García-Romero E. Flavonol profiles for grape and wine authentication. In: Ebeler SE, Takeoka GR, eds. Progress in authentication of food and wine. Washington, DC: American Chemical Society; 2011. pp 113-29.

29. Gómez-Alonso S, García-Romero E, Hermosín-Gutiérrez I. HPLC analysis of diverse grape and wine phenolics using direct injection and multidetection by DAD and fluorescence. J Food Comp Anal 2007;20:618-26.

30. Castillo-Muñoz N. Perfiles de flavonoides y otros compuestos flavonoideos para la autenticidad y diferenciación varietal de uva (V. vinifera) y Vino. Ciudad Real: Castilla-La Mancha University; 2010. 